\title{
Psychiatrists' education in psychology: jackdaw or sponge?
}

In his book The Organisation of Behaviour (1949), Donald Hebb remarked that: "If some psychologists jibe at the physiologist for a bedfellow, many physiologists would agree with them heartily.' Much the same could be said of any proposed betrothal between psychologist and psychiatrist. Theirs has been an erratic and tempestuous relationship in which heated disputes and fervent antipathy have been punctuated by protestations of warmth, high regard, and good intention. Although a delicate peace has appeared to settle upon the relationship in recent years, as the two parties mellowed into a comfortable middle age, the terms of the relationship are constantly being re-negotiated: witness the recent British Psychological Society - Royal College of Psychiatrists joint meeting, entitled 'Psychiatrists and psychologists: cooperation or confrontation?'.

Central to a better understanding between the two parties is the need for improved education, both of psychiatrists in psychology and psychologists in psychiatry. The former was the topic of an earlier conference (AUTP, 1982), and is the concern of the present paper, but it should be emphasized that the latter (psychologists' education in psychiatry) also requires close scrutiny.

Any discussion of psychiatrists' education in psychology needs to consider three aspects: first, psychology as science, purporting to stand in relation to psychiatry in much the same way that physiology does to medicine; secondly, psychology as technology, providing a set of techniques of use to clinicians; and, thirdly, psychology in relation to medical and psychiatric education in general, because the problems of teaching it are inseparable from the wider problems of medical education.

\section{PSYCHOLOGY AS SCIENCE}

In 1926, Bertrand Russell felt able to proclaim that: 'Scientific psychology has shown that flogging on weekdays and sermons on Sundays do not constitute the ideal technique for production of virtue (in the child).' Russell was less than scrupulous about his references but, in the same year, Freud was awarded his Honorary Membership of the British Psychological Society for his 'eminent contributions to the science of psychology' (signed by Spearman and prominently displayed in his Viennese waiting room) and, presumably, these two events may not have been wholly unrelated.

Since that time, many psychiatrists have attempted to straddle the two disciplines. Some have emphasized the research techniques which psychology offers clinical psychiatry, e.g. Hamilton (1973) and Pond (1982). On the other hand, Lewis (1953) went much further than this, defining psychiatry as concerning itself with deficits of 'psychological part-function', a definition which emphasized that central to the problems of psychiatry are the problems of psychology. In view of this, it is disappointing how considerable is the gap which still remains between the psychological study of part-function and the psychiatric study of disordered states, a gulf previously acknowledged by both Jaspers (1959) and Zangwill (1973). Equally regrettable is the fact that, even in the discussion of clinical topics, there often exist two parallel, but largely separate literatures, each referred to almost exclusively by the members of either profession. To break down such dichotomies should be a principal aim of teaching psychology to psychiatrists.

In 1982 the Association of University Teachers of Psychiatry published guidelines on the teaching of sciences 'basic' to psychiatry (AUTP, 1982). A substantial portion of these guidelines was devoted to psychology, and they were subsequently adopted by the Royal College of Psychiatrists. The document was strongly prescriptive, specifying what proportion of total teaching time should be

\footnotetext{
${ }^{1}$ Address for correspondence: Dr M. D. Kopelman, Department of Psychiatry, Institute of Psychiatry, De Crespigny Park, Denmark Hill, London SE5 8AF.
} 
devoted to each discipline, and indicating which topics 'must be known thoroughly... required ... understood . . . not covered comprehensively' etc. Although an earlier draft of the guidelines had argued that trainees should not be required to learn a superficial version of a degree course for undergraduate psychologists, the final draft reads very much like the first eighteen months of such a course. Very little attempt was made to suggest links between psychological studies and general training in clinical psychiatry.

In fact, psychological and psychiatric studies could be integrated much more imaginatively than was even hinted at in that document. Topics central to psychology (e.g. the structure and functioning of human memory) should be allowed to lead naturally into discussion of clinical topics (e.g. the nature of the deficits in amnesia and dementia); just as clinical topics (e.g. the effects of brain trauma at different ages) should stimulate discussion of the underlying theoretical issues (see, for example, Rutter, 1982). The study of child development can be closely integrated with child psychiatry; the study of attention with an account of its alterations in hyperkinesis and schizophrenia; the study of perception with its abnormalities in sensory and sleep deprivation and in mental illness; the study of language with discussion of the developmental disorders and possible linguistic abnormalities in the psychoses; and the study of memory and intelligence with the study of dementia. Such notions are hardly novel or radical, but the 1982 guidelines (like the current MRCPsych. format) exemplify a system in which psychology and other sciences are viewed as not just 'basic to' but 'apart from' clinical psychiatry. That way, the dichotomies remain.

\section{PSYCHOLOGY AS TECHNOLOGY}

Psychiatrists' current education in psychology often appears to reflect the days when psychologists were regarded as those backroom technicians, analogous to haematologists or biochemists, except that they forgot, or worse refused, to wear their white coats. Thus, there is teaching about intelligence and memory testing, about neuropsychological and personality assessment, and about behaviour and cognitive therapy. However, this approach tends to fall between two stools because, on the one hand, it often fails to convey any of the excitement and interest of psychology as science while, on the other, failing to provide trainees with the skills and techniques which they require.

The techniques of psychology can be divided, of coure, into assessment and treatment. While psychologists frequently complain that psychiatrists do not know the appropriate indications for and interpretation of psychological testing (a complaint which probably has considerable justification), they sometimes appear to exert themselves remarkably little to put the situation right. Admittedly, cognitive assessment is a relatively dull topic to teach but, if done with imagination, it should be possible to convey the main principles in the context of individual case studies and to use the opportunity to introduce the more interesting findings from psychological research.

Likewise, most trainees will have attended innumerable lectures about behaviour therapy. These usually seem to present the behaviour therapies as having been logically derived from something called 'modern learning theory', a somewhat old-fashioned view, now modified even by Eysenck (Eysenck, 1975). What is really required is supervision in behavioural assessment, in setting up and carrying through a behavioural programme, and in evaluating its efficacy. Although the outcome of 'outcome' research in psychotherapy remains as subject as ever to personal interpretation (contrast Bloch, 1982 and Prioleau et al. 1983), it is arguable that it is anachronistic for there to be such an imbalance between the widespread availability of supervision in psychotherapy and the paltry availability of training in behavioural techniques. Moreover, it may soon become necessary to provide a training in the various 'cognitive' therapies, recently reviewed by Williams $(1984 a, b)$. The precise role of these latter techniques within clinical practice remains to be fully elucidated (Williams, 1984b), but it would be regrettable indeed if they were allowed to become the exclusive preserve of psychologists, having been initiated by a psychiatrist (Beck, 1976) and representing one of the healthier products of collaboration. Indeed, both behavioural and cognitive therapies are skills for which some joint professional training scheme might be contemplated, were it not that senior 
members of both professions, perhaps fearing the jackdaw, tend to become strangely mute at such a suggestion.

\section{PSYCHOLOGY WITHIN PSYCHIATRIC EDUCATION}

Both the content and manner in which a subject is taught are determined not only by lists of 'guidelines' but by the nature of any proposed examination. However undesirable, an examination determines the way in which a trainee views a subject, and Brook (1973) reported that some trainees seemed to think they 'knew psychology' when they had passed the old Part 1 DPM exam. Regrettably, psychology is now examined almost exclusively by multiple-choice questionnaire (MCQ).

Psychologists themselves do not employ MCQs in their own examinations, despite (or, perhaps, because of ) the fact that the concepts of reliability and validity derive from educational psychology. At the inception of these examinations, Russell \& Walton (1970) reported a long, and indeed agonized, discussion in which such eminent figures as Sir Denis Hill, Sir Martin Roth, and Professors Shepherd and Walton expressed considerable scepticism concerning whether MCQs should be used to examine anything other than the more factual and organic aspects of psychiatry. It was suggested that there was an urgent need to monitor their validity. Elsewhere, Sir George Pickering (1978), the former Regius Professor of Medicine at Oxford, expressed himself more bluntly, characterizing these examinations as requiring 'answers without evidence, the very negation of scholarship, . . . a terrifying return to authoritarianism and the tyranny of dogma', and asking 'Are we on the threshold of another Dark Age?'

There are two principal reasons why these examinations have survived such onslaughts, and have become so beloved of examiners. First, they are easily marked by computer, thereby sparing considerable dreary labour; and, secondly, there is reputed to be a large literature establishing their superior reliability and fairness over other forms of examination. ('They . . produce results . . that depend on your knowledge of the subject itself rather than your knowledge of the examiner or your social or linguistic graces. They are more fair (sic) to more candidates. . '; Royal College of Psychiatrists, 1980.) While their ease of marking is indisputable, the claim of superior reliability and fairness is much more equivocal. Several studies have shown that, when certain conditions are fulfilled, the inter-rater reliability of essay examinations can approach, or even exceed, the split-half reliability of MCQ examinations (Ferguson et al. 1970; Lipton \& Huxham, 1970; Dudley, 1973). The more important and difficult issue of validity has been almost entirely neglected, although some educationalists have attempted to validate MCQs against the essay examinations they seek to supplant, a somewhat perplexing procedure. Not surprisingly, Ferguson et al. (1970) found that MCQ performance is an excellent predictor of MCQ performance, and essay performance of essay performance, but neither is very good at predicting the other. Moreover, Meyer $(1934,1935)$ established long ago what many contemporary candidates will recognize: namely, that work in preparation for essay examinations tends to be systematically organized, and is subsequently well retained, whereas that in preparation for MCQs is by necessity much more fragmented, and is therefore rapidly forgotten.

This issue touches upon a wider and more critical question: should the problems of psychology, or any other 'basic' science, really be discussed within the didactic format of traditional medical education? Is it either necessary or desirable to draw up lists of what should be 'thoroughly known', moderately known, or only mildly known, and to examine this knowledge by a computerized test? Or should postgraduate education attempt something more ambitious, but immensely more important: namely, to try to stimulate interest, to provoke excitement, and to generate enthusiasm, so that the student is encouraged to pursue the subject for himself. The most damning criticism of many teachers in medical education is not just that they fail to inspire their students, but that, heavily defended behind a barricade of syllabuses and examinations, they do not even try. Meanwhile, the prophets of the MCQ abrogate all responsibility, confusing their medium for the message, in an 
absurd claim to have occupied 'an area previously reserved for philosophers . . the definition of structure in medical education' (Buckley-Sharp \& Harris, 1972).

These remarks may appear naïve and idealistic to some, trite to others. Anticipating the former charge I have attempted to muster up some support:

\section{William James (1890)}

'In all pedagogy the great thing is to strike the iron while hot, to seize the wave of the pupil's interest. . . before its ebb has come. . . (to secure) a headwave of interest on which afterward the individual may float.'

\section{Sigmund Freud (1914)}

'It is hard to decide what affected us more . . . the sciences that we were taught, or . . the personalities of our teachers. It is true at least that . . . in many of us the path to the sciences led only through our teachers.'

\section{B. F. Skinner (1964)}

'Most students still study mainly to avoid the consequences of not studying. Even at university. . . the commonest pattern is to assign and test, in which it is never the student who fails, nor can it be, for assigning and testing is not really teaching at all ... Education is what survives when what has been learned has been forgotten.'

\section{Paul Meehl (1973)}

'(I do not) believe a person, even if basically bright, can be intellectually exciting unless he is intellectually excited. It astonishes me that so many persons enter academic life despite having what, to all appearances, is a rather feeble capacity for becoming excited about ideas.'

\section{Bertrand Russell (1935)}

'There is a charming tale of Chechov's about a man who tried to teach a kitten to catch mice. When it wouldn't run after them, he beat it, with the result that even as an adult cat it cowered with terror in the presence of a mouse. "This is the man" Chechov adds "who taught me Latin!".'

The pertinence of these quotations is emphasized by Pickering's (1978) report that many young doctors express disappointment with the low intellectual content of their undergraduate training, and the growing inflexibility of the postgraduate period, frequently complaining of boredom during their medical education. Pickering saw the problem as being too many subjects, too many lectures, and the development of so-called objective methods of examination. He wrote: 'Far more important than the details of the curriculum is the attitude of the teacher. Learning is easy if . . the process (is) exhilarating. . . The teacher's attitude should be to kindle the flame rather than fill the pot!'

\section{CONCLUSION}

In summary, central to many issues in psychiatry are the problems of psychology, and the teaching of both disciplines should be closely and imaginatively integrated. This entails training psychiatrists in some of the technical skills of psychology, rather than their simply learning about them - even though this may pose political problems, which Birley (1982) has labelled as the problem of the jackdaw. Education in psychology should certainly not consist of working through a syllabus, to be ticked off in an MCQ, but should aim to stimulate interest and to generate enthusiasm, and the failure to do so touches upon one of the most fundamental problems of medical education - which is the problem of the sponge.

MICHAEL D. KOPELMAN

This paper is based upon a talk given at an AUTP conference in 1982, convened by Dr J. L. T. Birley. I am grateful to Dr John Cutting for encouraging me to publish it and for reading the first draft. 


\section{REFERENCES}

Association of University Teachers of Psychiatry (1982). Guidelines: Sciences basic to psychiatry. Bulletin of the Royal College of Psychuatrists 6, 54-56.

Beck, A. T. (1976). Cognitive Therapy and the Emotional Disorders. International Universities Press: New York.

Birley, J. L. T. (1982). The psychiatrist learnıng psychology: sponge or jackdaw? Title of a symposium convened under the auspices of the Association of University Teachers of Psychiatry.

Bloch, S. (1982). Psychotherapy. In Recent Advances in Clinical Psychiatry, Vol. 4 (ed. K. Granville-Grossman), pp. 25-45. Churchill Livingstone: London.

Brook, P. (1973). Psychiatrists in Training. British Journal of Psychiatry. Special Publication No. 7. Headley Bros.: Ashford, Kent.

Buckley-Sharp, M. D. \& Harris, F. T. C. (1972). Scoring systems for MCQs (correspondence). British Journal of Medical Education 6, $170-172$.

Dudley, H. A. F. (1973). Multiple-choice tests: time for a second look? Lancet ii, 195-196.

Eysenck, H. J. (1975). Psychological theories and behaviour therapy. Psychological Medicine 5, 219-221.

Ferguson, A., Wright, M. A. \& McNicol, G. P. (1970). Appraisal of student performance: multıple-choice questions, essays, and 'short notes'. Britush Journal of Medical Education 5, 147-151.

Freud, S. (1914). Some reflections on schoolboy psychology. In Complete Works (standard edn) (ed. J. Strachey), Vol. 13, pp. 239-244. Hogarth: London (1955).

Hamilton, M. (1973). Psychology in society: ends or end? Bulletin of the British Psychological Society 26, 185-189.

Hebb, D. O. (1949). The Organisation of Behaviour. John Wiley \& Sons: New York.

James. W. (1890). The Principles of Psychology, Vol. 2. Dover Publications: New York (1950).

Jaspers, K. (1959). General Psychopathology (seventh edn) (transl. J. Hoenig and M.W. Hamilton). Manchester University Press: Manchester (1963).
Lewis, A. J. (1953). Health as a social concept. British Journal of Sociology 4, 109-124

Lipton, A. \& Huxham, G. J. (1970). Comparison of multiple-choice and essay testing in preclinical physiology. British Journal of Medical Education 4, 228-238.

Meehl, P. E. (1973). Why I do not attend case conferences. In Psychodiagnosis: Selected Papers. University of Minnesota Press: Minneapolis.

Meyer, G. (1934). An experimental study of the old and new types of examination I. Journal of Educational Psychology 25, 641-661.

Meyer, G. (1935). An experimental study of the old and new types of examination 2. Journal of Educational Psychology 26, 30-40.

Pickering, G. (1978). Quest for Excellence in Medical Education: a Personal Survey. Oxford University Press: Oxford.

Pond, D. (1982). Psychology: prop or profession? Bulletin of the British Psychological Society 35, 49-55.

Prioleau, L., Murdock, M. \& Brody, N. (1983). An analysis of psychotherapy versus placebo studies. Behavioral and Brain Sctences 6, 275-310.

Royal College of Psychiatrists (1980). Handbook for Inceptors and Trainees in Psychiatry. Headley Bros.: Ashford, Kent.

Russell, B. ([926), On Education. Allen \& Unwin: London.

Russell, B. (1935). Freedom versus authority in education. In Sceptical Essays. Allen \& Unwin: London.

Russell, G.F.M. \& Walton, H. J. (1970). The Training of Psychiatrists. Brutish Journal of Psychiatry, Special Publication No. 5. Headley Bros.: Ashford, Kent.

Rutter, M. (1982). Developmental neuropsychiatry: concepts, issues, prospects. Journal of Clinical Neuropsychology 4, 89-112.

Skinner, B. F. (1964). New methods and new aims in teaching. New Scientist No. 392, 483-484.

'Villiams, J. M. G. (1984a). The Psychological Treatment of Depression. Croom Helm: London.

Williams, J. M. G. (1984b). Cognitive-behaviour therapy for depression: problems and perspectives. British Journal of Psychiatry 145, 254-262.

Zangwill, O. L. (1973). Psychology in relation to psychiatry. Psychological Medicine 3, 133-140. 